\title{
Action Simulation Plays a Critical Role in Deceptive Action Recognition
}

\author{
Emmanuele Tidoni, ${ }^{1,2}$ Sara Borgomaneri, ${ }^{3,4,5}$ Giuseppe di Pellegrino, ${ }^{4,5}$ and Alessio Avenanti ${ }^{1,4,5}$ \\ ${ }^{1}$ Istituto di Ricovero e Cura a Carattere Scientifico (IRCCS), Fondazione Santa Lucia, 00179 Rome, Italy, ${ }^{2}$ Dipartimento di Psicologia, Sapienza Università di \\ Roma, 00185 Rome, Italy, ${ }^{3}$ Neuroimaging Center, Department of Neuroscience, University of Groningen, 9713 AW Groningen, The Netherlands, ${ }^{4}$ Centro \\ Studi e Ricerche in Neuroscienze Cognitive, Polo Scientifico-Didattico di Cesena, Alma Mater Studiorum Università di Bologna, 47521 Cesena, Italy, and \\ ${ }^{5}$ Dipartimento di Psicologia, Alma Mater Studiorum Università di Bologna, 40127 Bologna, Italy
}

The ability to infer deceptive intents from nonverbal behavior is critical for social interactions. By combining single-pulse and repetitive transcranial magnetic stimulation (TMS) in healthy humans, we provide both correlational and causative evidence that action simulation is actively involved in the ability to recognize deceptive body movements. We recorded motor-evoked potentials during a faked-action discrimination (FAD) task: participants watched videos of actors lifting a cube and judged whether the actors were trying to deceive them concerning the real weight of the cube. Seeing faked actions facilitated the observers' motor system more than truthful actions in a body-part-specific manner, suggesting that motor resonance was sensitive to deceptive movements. Furthermore, we found that TMS virtual lesion to the anterior node of the action observation network, namely the left inferior frontal cortex (IFC), reduced perceptual sensitivity in the FAD task. In contrast, no change in FAD task performance was found after virtual lesions to the left temporoparietal junction (control site). Moreover, virtual lesion to the IFC failed to affect performance in a difficulty-matched spatial-control task that did not require processing of spatiotemporal (acceleration) and configurational (limb displacement) features of seen actions, which are critical to detecting deceptive intent in the actions of others. These findings indicate that the human IFC is critical for recognizing deceptive body movements and suggest that FAD relies on the simulation of subtle changes in action kinematics within the motor system.

\section{Introduction}

Understanding others' intentions is a key feature of social daily life. Interpersonal interactions may require one to accurately judge from nonverbal behavior whether a person is honest or deceitful, and careful assessment of others' bodily movements may be critical to detecting deceptive intentions (Runeson and Frykholm, 1983; Ekman and O'Sullivan, 1991; Vrij, 2004). However, the functional and neural mechanisms underlying the recognition of deceptive body movements [faked actions (FAs)] are poorly understood.

FA recognition requires the reading of subtle action cues that violate observers' predictions about the kinematics of the observed action (Bond et al., 1992; Frank and Ekman, 1997; Sebanz and Shiffrar, 2009), and thus it may involve comparisons with stored internal models of the observed action (Wolpert et al.,

\footnotetext{
Received April 8, 2011; revised Nov. 9, 2012; accepted Nov. 9, 2012.

Author contributions: E.T., G.d.P., and A.A. designed research; E.T. and S.B. performed research; E.T., S.B., and A.A. analyzed data; E.T., G.d.P., and A.A. wrote the paper.

This work was supported by grants from the University of Bologna (Ricerca Fondamentale Orientata), the Ministero Istruzione Università e Ricerca (PRIN 2008, protocol number: 2008YTNXXZ), and the Istituto Italiano di Tecnologia (SEED 2009, protocol number: 21538), awarded to A.A. and G.d.P., and grants from the Ministero della Salute (Bando Ricerca Finalizzata Giovani Ricercatori 2010, protocol number: GR-2010-2319335) and the Ministero Istruzione Università e Ricerca (Futuro in Ricerca 2012, protocol number: RBFR12F0BD), awarded to A.A. We thank Gabriele Gattucci for his help in computer programming and Brianna Beck for her comments on the manuscript. The authors declare no competing financial interests.

Correspondence should be addressed to Alessio Avenanti, Centro di studi e ricerche in Neuroscienze Cognitive, Viale Europa 980, 47521, Cesena, Italy. E-mail: alessio.avenanti@unibo.it.

DOI:10.1523/JNEUROSCI.2228-11.2013

Copyright $\odot 2013$ the authors $\quad 0270-6474 / 13 / 330611-13 \$ 15.00 / 0$
}

2003). Transcranial magnetic stimulation (TMS) offers the unique possibility to noninvasively stimulate the motor cortex and assess its activity by recording motor-evoked potentials (MEPs). Studies have shown that watching others' actions increases the amplitude of MEPs recorded from those muscles that would be involved in the observed actions (Fadiga et al., 2005), suggesting that seeing actions triggers action resonance in the motor system. Notably, the motor system shows an anticipatory bias in the simulation of future phases of observed actions (Borroni et al., 2005; Urgesi et al., 2010), and it is modulated by watching erroneous actions (Aglioti et al., 2008). Thus, when seeing FAs, the detection of kinematic cues violating the predicted action may specifically modulate motor resonance processes.

The inferior frontal cortex (IFC, including inferior frontal gyrus and ventral premotor cortex) represents a key region within the neural network mediating action simulation [i.e., the action observation network (AON); Avenanti and Urgesi, 2011]. This region modulates action resonance processes (Avenanti et al., 2007, 2012b), is recruited when processing kinematic (Saygin et al., 2004; Majdandzic et al., 2009) and goal (Gazzola et al., 2007; Cattaneo et al., 2010) components of seen actions, and is sensitive to action intentionality (Iacoboni et al., 2005; de Lange et al., 2008). Notably, the only previous study exploring neural correlates of deceptive intentions recognition has shown that neural activity in IFC discriminates between FAs and truthful actions (TAs) (Grèzes et al., 2004); however, this IFC activation fell outside the classical AON. Moreover, a similar modulation was 
found in the temporoparietal junction (TPJ), a region often associated with mental state attribution (Frith and Frith, 2006; Saxe and Powell, 2006). Critically, imaging cannot establish a direct causal link between brain and function, and to date no studies have tested whether the IFC (or TPJ) is necessary for recognition of FAs. Here, we provide correlational and causative evidence that action simulation is actively involved in such recognition. We recorded MEPs to single-pulse TMS to directly investigate whether observation of FAs modulates action resonance processes when performing a faked-action-discrimination (FAD) task. Then, we tested the critical role of the AON sector of IFC (and of TPJ, as a control) in recognizing FAs and TAs, by using online repetitive TMS (rTMS) during performance of a FAD task and a control task.

\section{Materials and Methods Participants}

A total of 138 healthy subjects took part in the study. Sixty subjects (28 women; age range, 19-27 years) participated in one of three TMS experiments, 10 subjects ( 6 woman; age range, $24-39$ years) participated in an action execution experiment, and 68 subjects (39 women; age range, $20-35$ years) were tested in one of four pilot studies. All the subjects were right-handed according to a standard handedness inventory (Briggs and Nebes, 1975), had normal or corrected-to-normal visual acuity in both eyes, and were naive as to the purposes of the experiment. None of the participants had neurological, psychiatric, or other medical problems or any contraindication to TMS (Rossi et al., 2009). Participants provided written informed consent, and the procedures were approved by the ethics committee at the Psychology Department of Bologna University and were in accordance with the ethical standards of the 1964 Declaration of Helsinki. No discomfort or adverse effects during TMS were reported or noticed.

\section{General aims and study design}

Studies of deception detection traditionally have focused on verbal communication. Nevertheless, people also commonly deceive others through nonverbal cues. Previous research has shown that intentions can be inferred from the ways in which people move their bodies (Ekman and O’Sullivan, 1991; Bond et al., 1992; Frank and Ekman, 1997; Vrij, 2004; Becchio et al., 2012). In the present study, we investigated the functional and neural mechanisms underlying recognition of deceptive body movements (FAs; i.e., movements in which the body is consciously used as an instrument for deception). We used a well established procedure in which an actor is asked to provide deceptive information (FAs) or truthful information (TAs) regarding the action he/she is performing using his/her body movements only (Runeson and Frykholm, 1983; Grèzes et al., 2004). Specifically, we asked actors to grasp, lift, and place a cube that could be light or heavy and, in some cases (FAs), we instructed the actors to lift the cube as if it had a weight different from the actual weight. Thus, FAs were actions in which the actors pretended to lift a light cube as if it were a heavier one or to lift a heavy cube as if it were a lighter one. Conversely, TAs were actions in which the weight appearance that could be estimated by seeing the actor's movements reflected the cube's actual weight. In three main TMS experiments, participants were tested in an FAD task in which they saw actors lifting and placing a cube and had to judge whether the actor was providing deceptive information (FAs) or truthful information (TAs) concerning the weight of the lifted cube. It should be noted that this task was not designed to explore deception recognition in general but to investigate the mechanisms underlying recognition of deceptive body movements, especially deceptive hand movements.

In Experiment 1, we used a correlational TMS approach and recorded MEPs to explore motor system activity during FAD task performance. In Experiments 2 and 3 we used a causative approach and investigated the effect of TMS-induced virtual lesions over IFC or TPJ on performance in the FAD task and in a difficulty-matched control task that did not require participants to assess the presence of deceptive intents. Our findings suggest that action simulation activity in the motor system is sensitive to observed deceptive movements and is critical to visually discriminating between FAs and TAs.

\section{Experiment 1: single-pulse TMS and EMG during action observation and execution}

Twenty-five subjects were tested in the first experiment. Fifteen subjects (6 women; mean age, 21.5 years; range, 19-25 years) took part in a single-pulse TMS session aimed at exploring motor system modulation during active recognition of FA and TA video clips. To enable investigation of motor resonance with a high degree of muscle specificity, we focused in the present experiments on FAs/TAs performed with the dominant hand, in contrast to the fMRI study of Grèzes and colleagues (2004) in which a FAD task showing full body actions was used. In that study, discrimination of FAs/TAs modulated IFC and TPJ activity in the right hemisphere, in keeping with the notion that full-body actions recruit right-lateralized action observation neural networks (Van Overwalle and Baetens, 2009). In contrast, evidence indicates that action simulation activity detected with single-pulse TMS is largely contralateral with respect to the observed effectors (Aziz-Zadeh et al., 2002; for convergent imaging evidence, see also Shmuelof and Zohary, 2005; Gazzola and Keysers, 2009; Cabinio et al., 2010). Thus, because our stimuli depicted a right hand, in Experiment 1 we stimulated the left motor cortex and recorded MEPs from the right hand. Two muscles were considered: (1) the first dorsal interosseous (FDI), which is directly involved in controlling the strength of the grip during lifting and placing and was found to be modulated by the object's weight during observation of lifting (Alaerts et al., 2010a; Senot et al., 2011); and, as control muscle, (2) the flexor carpi radialis (FCR), which was found not to be modulated by the object's weight during lifting observation and execution (Alaerts et al., 2010a,b). To compare action observation with execution, the EMG activity from the right FDI and FCR muscles of 10 additional subjects ( 6 women; mean age, 27.6 years; range, 24-39 years) was recorded during the execution of the same actions depicted in the video clips.

\section{Transcranial magnetic stimulation and electromyography} recording during action observation

MEPs were recorded simultaneously from the right FDI and FCR by means of a Biopac MP-150. EMG signals were bandpass filtered (30-500 $\mathrm{Hz}$ ), digitized (sampling rate at $5 \mathrm{kHz}$ ), and stored on a computer for offline analysis. Pairs of $\mathrm{Ag}-\mathrm{AgCl}$ surface electrodes were placed in a belly-tendon montage on each muscle, with two further ground electrodes on the wrist and on the elbow. A figure-of-eight coil (diameter, 70 $\mathrm{mm}$ ) connected to a Magstim Rapid ${ }^{2}$ stimulator (Magstim) was placed over the left motor cortex. The intersection of the coil was placed tangentially to the scalp with the handle pointing backward and laterally at a $45^{\circ}$ angle away from the midline. This orientation induced a posterior-anterior current in the brain, which tends to activate corticospinal neurons indirectly via excitatory synaptic inputs (Di Lazzaro et al., 1998). The orientation was chosen based on the finding that the lowest motor threshold is achieved when the induced electric current in the brain is flowing approximately perpendicular to the central sulcus (Brasil-Neto et al., 1992; Mills et al., 1992). Participants wore a tight-fitting bathing cap on which the coil was moved over the left hemisphere to determine the FDI optimal scalp position (OSP). The OSP was then marked on the cap to ensure correct coil placement throughout the experiment. Stimulation intensity during the recording sessions was $120 \%$ of the resting motor threshold (rMT), defined as the lowest stimulus intensity able to evoke 5 of 10 MEPs with an amplitude of at least $50 \mu \mathrm{V}$ (Rossini et al., 1994) in the higher threshold muscle, the FCR. This way a stable signal could be recorded from both muscles. Participants' rMT ranged from $41 \%$ to $74 \%$ (mean \pm SEM: $58 \pm 2.16 \%$ ) of the maximum stimulator output.

\section{Stimuli and task}

A nonprofessional male actor was videotaped while reaching, grasping, lifting, and placing a cube on a shelf with his right hand (Fig. 1). Two cubes with identical visual appearance (size, $5 \times 5 \times 5 \mathrm{~cm}$ ) but different weights (50 or $650 \mathrm{~g}$ ) were used. During the first part of the recording 


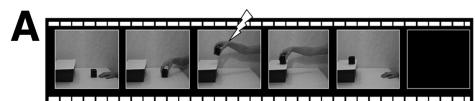

Did the actor try to deceive you?

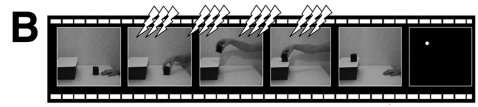

Did the actor try to deceive you?

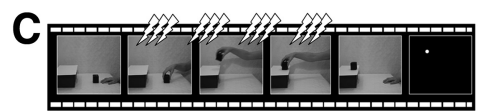

Was the dot on the hand trajectory?
D

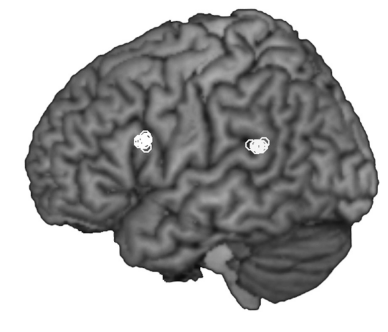

Figure 1. $\boldsymbol{A}-\boldsymbol{C}$, Timeline for the FAD task in Experiment $1(\boldsymbol{A})$, Experiments 2 and $3(\boldsymbol{B})$, and for the $S C$ task in Experiments 2 and 3 (C). D, White circles, IFC and TPJ stimulation sites reconstructed on a standard template using MRIcro (v1.40; http://www.mricro.com).

session, the experimenter correctly informed the actor about the cube's weight (TA). In a second part of the recording, the experimenter correctly informed the actor about the cube's weight and instructed him to lift the cube as if it had a different weight (FA); that is, in some trials the actor pretended to lift the light $(50 \mathrm{~g})$ cube as if it weighed $650 \mathrm{~g}$ (apparently heavy weight), and in other trials he pretended to lift the heavier ( $650 \mathrm{~g}$ ) cube as if it weighed $50 \mathrm{~g}$ (apparently light weight). Four types of videos were created following a 2 (weight appearance: light, heavy) $\times 2$ (action type: TA, FA) design: apparently light TA, apparently heavy TA, apparently light FA, apparently heavy FA. For TAs, weight appearance reflected the cube's actual weight, while for FAs weight appearance provided deceptive information about the real weight. The clips were blackand-white videos of $5000 \mathrm{~ms}$ duration (30 frames per second) subtending $17.3 \times 13.2^{\circ}$ of visual angle. We used black-and-white videos to prevent local changes in skin tone due to hand contraction from conveying information about the real weight of the cubes. Videos were carefully checked for the absence of local hand information. Moreover, kinematic analyses (see below) were performed to ensure that movies contained subtle movement cues that could be used to detect actor's intent to deceive.

Two different versions of each visual stimulus type were used in the single-pulse TMS session, based on the result of a pilot psychophysical experiment performed on 25 subjects ( 19 females; mean age, 25.88 years; range, 20-33 years) not participating in the TMS study. This psychophysical experiment was aimed at selecting TA and FA clips recognized with $\sim 75 \%$ accuracy among an initial sample of 60 clips. Thus a total of eight different clips were presented in Experiment 1. To maximize the probability that, during action observation, perceivers would access stored internal models of the observed actions, in a preliminary phase of Experiment 1, participants were asked to lift the same two cubes used in the video clips ( $\sim 20$ times each, random presentation). Then they performed the FAD task (Fig. $1 A$ ): subjects were informed that they had to observe an actor lifting a cube, and that in some cases the actor lifted the cube as if it were heavier or lighter than its actual weight. Participants' task was to decide (forced choice) whether or not the actor was trying to deceive them concerning the cube's real weight. The experiment began with a practice block of 24 trials ( 3 presentations $\times 8$ videos; accuracy \pm SEM, $75 \pm 2 \%$ ) during which responses were collected by keypress. During MEP recording, participants provided verbal responses ("Yes/ No") only at the end of each video, while the experimental question was on the screen ("Did the actor try to deceive you?"). The very same procedure was used in the pilot psychophysical study except that all the responses were collected by keypress.

\section{Procedure}

Action observation. The experiment was programmed using custom software (developed in C\#) to control the video-clip sequence and trigger TMS. Participants were tested in seven TMS blocks. The first and the last block (15 trials each) served as baseline: subjects kept their eyes closed with the instruction to imagine watching a sunset at the beach (Fourkas et al., 2008; Borgomaneri et al., 2012). In the remaining experimental blocks ( 32 trials each), participants were presented with the FAD task.
Each trial started with a gray screen (duration, $1000 \mathrm{~ms}$ ) followed by the clip (5000 ms); during the clip, a TMS pulse was delivered and MEPs from the FDI and FCR were recorded. For each trial, a TMS pulse was randomly delivered in the second half of the clip (covering the lifting and placing phase).

The overall experimental design included a combination of two muscles (FDI, FCR), two action types (TA, FA), and two apparent weights (light, heavy). Each video clip was repeated 20 times, resulting in a total of 160 trials (equally) distributed across the five blocks (40 MEPs per condition and muscle). Video clips were presented in a random order.

To avoid changes in excitability due to verbal response (Tokimura et al., 1996; Meister et al., 2003), participants were invited to answer only at the end of each clip, a few seconds after the TMS pulse. After response, the screen appeared black for 4-6 s. This way the interpulse interval was $>10 \mathrm{~s}$, thereby avoiding changes in motor excitability due to TMS per se (Chen et al., 1997). This was directly confirmed by the lack of changes in MEP amplitude between the first (mean amplitude \pm SEM: FDI, $1.42 \pm 0.24 \mathrm{mV}$; FCR, $0.42 \pm 0.09 \mathrm{mV}$ ) and the last baseline block (FDI, $1.77 \pm 0.25 \mathrm{mV}, t_{13}=-1.53, p=0.15$; FCR, $0.55 \pm 0.12 \mathrm{mV}$, $\left.t_{13}=-1.57, p=0.14\right)$.

Action execution. To compare action observation with execution, 10 additional subjects (not participating in the single-pulse TMS experiment) were asked to reach, grasp, lift, and place a cube on a shelf with their right hand while EMG activity from the right FDI and FCR was recorded by means of the electromyograph. The very same cubes (size, $5 \times 5 \times 5 \mathrm{~cm}$; weight, 50 and $650 \mathrm{~g}$ ) and apparatus of the TMS session were used. Four types of actions were performed: apparently light TAs, apparently heavy TAs, apparently light FAs, and apparently heavy FAs. Each condition included 12 action execution trials that were performed in two separate blocks of six trials each. Thus, eight blocks were carried out, one for each movie of the TMS session. In each block, a brief practice phase was initially performed. During the practice phase, participants were asked (1) to watch one of the movies depicting a FA/TA on a light/ heavy cube ( 6 times) and (2) to perform the observed action on the same cube (as shown in the movie) during online presentation of the clip (6 times). After this practice phase, subjects were asked to keep lifting the cube in that way (FA/TA) without any movie (12 times) and their EMG signal was recorded. In each trial, subjects placed the arm and hand in a resting position with muscles relaxed. Online EMG signal was visually inspected to check muscle relaxation. Subjects performed the action after a go signal. A custom-made electrical circuit signaled when the cube was lifted from the initial position and placed on the final position. This procedure allowed assessment of action execution using the same temporal frame as that used for MEP recording during action observation.

\section{Data handling}

Kinematic parameters. Spatiotemporal (arm acceleration, duration), configurational (wrist angle, grip aperture), and spatial (arm vertical peak) kinematic parameters of the actor's right arm were extracted on a frame-by-frame analysis using a custom Matlab script (MathWorks) and processed offline. Maximal grip aperture before and while grasping the cube was measured as the distance between the tips of the thumb and of the index finger (measured in pixels and converted in centimeters). Arm vertical peak and arm acceleration was measured with reference to the position of dorsal aspect of the wrist (in centimeters). For grip aperture and arm vertical peak data, a factorial ANOVA with Action Type (TA, FA) and Apparent Weight (light, heavy) as between-movie factors was performed. For the other kinematic parameters, we also considered the specific phase of the movement and distinguished between lift and place phases. The lifting phase lasted from the start of cube displacement to the wrist vertical peak. The placing phase lasted from arm vertical peak until the end of object displacement as the object was put on the shelf (Alaerts et al., 2010b). Arm acceleration was measured with reference to the po- 
sition of the dorsal aspect of the wrist. Movement duration (in milliseconds), arm acceleration (in centimeters per second squared), and wrist angle (in degrees) were entered into mixed-model ANOVAs with Action Types (TA, FA) and Apparent Weight (light, heavy) as between-movie factors, and Phase (lift, place) as a within-movie factors. In these and in all the following ANOVAs, post hoc analysis was performed by means of Newman-Keuls test.

EMG during action execution. EMG data were processed offline. For each trial, the root mean square of the rectified EMG signal was measured from lifting to placing. The root mean square of the rectified EMG signal in the $100 \mathrm{~ms}$ preceding each go signal was considered as baseline. The mean EMG signal for each condition was expressed as a percentage from the baseline (EMG ratios) and analyzed using a three-way repeatedmeasure ANOVA with Muscle (FDI, FCR), Action Type (TA, FA), and Apparent Weight (light, heavy) as within-subject factors. To ensure that any change in EMG level during execution was not due to changes in preceding muscle tone, a further Muscle $\times$ Action Type $\times$ Apparent Weight ANOVA was performed on baseline EMG level.

MEPs during action observation. One subject was discarded due to technical failure in MEP recording. Neurophysiologic data were processed offline. MEPs associated with erroneous responses (21\%) were removed from the analysis; moreover, trials with EMG background activity of $>10 \mu \mathrm{V}$ in the $100 \mathrm{~ms}$ interval before the TMS pulse were separately discarded for FDI (11\%) and FCR (8\%). This procedure left $>24$ MEPs per experimental condition, muscle, and subject. The peakto-peak mean MEP amplitude (in millivolts) in each experimental condition and baseline block was measured. To reduce skewness, a logarithmic transformation was applied to mean MEP amplitudes $[\log ($ value +1$)]$ and MEP ratios (percentage of baseline blocks) were computed for each experimental condition. MEP ratios were entered into a three-way repeated-measures Muscle $\times$ Action Type $\times$ Apparent Weight ANOVA. To ensure that any MEP modulation was not due to changes in EMG background, a similar Muscle $\times$ Action Type $\times$ Apparent Weight ANOVA was conducted on the root mean square of the rectified EMG signal recorded in the $100 \mathrm{~ms}$ preceding the TMS pulse.

\section{Experiment 2 and 3: repetitive TMS during action observation}

To investigate the neural bases of FA recognition, in Experiment 2 we used online rTMS and tested the role of IFC (IFC stimulation group: 15 subjects; 7 women; mean age, 21.9 years; range, 20-24 years) and TPJ (TPJ stimulation group: 15 subjects; 8 women; mean age, 22.0 years; range, $19-25$ years) in FAD. An additional IFC group (15 participants; 7 women; mean age, 21.8 years; range, $20-27$ years) was tested in Experiment 3.

In both experiments, we tested the hypothesis that the anterior node of the AON is critical for FAD. Experiment 1 showed that our FAD task modulated the left motor cortex, confirming the rationale for selecting the left hemisphere during processing of right-hand actions (Aziz-Zadeh et al., 2002; Shmuelof and Zohary, 2005). Studies suggest that during action observation, the left motor cortex is influenced by activity from the action observation sector of the left IFC (Avenanti et al., 2007, $2012 \mathrm{~b}$ ). This region is known to be active during action observation and execution (Buccino et al., 2004; Costantini et al., 2005; Molnar-Szakacs et al., 2005; Gazzola et al., 2007; Kilner et al., 2009) and interference with this area impairs visual discrimination of static pictures depicting different actions/body postures (Urgesi et al., 2007a,b; Candidi et al., 2008). In view of this, in Experiments 2 and 3 we used rTMS to stimulate the action simulation sector of the left IFC.

To avoid unwanted effects of hemispheric differences, as an active control site, we stimulated the TPJ in the same hemisphere. Notably, the left TPJ is a key region of a neural network involved in mentalizing (Ciaramidaro et al., 2007). The left TPJ is not only recruited when reasoning about the mental states of others (Saxe and Powell, 2006; Young et al., 2011), but is also specifically active when reading others' intentions during lying judgments (Harada et al., 2009) and, critically, it is also necessary for correct mentalizing, since lesions in this region impair the ability to make inferences about others' beliefs and to read others' intentions and desires (Apperly et al., 2004; Samson et al., 2004; Chiavarino et al., 2010). Therefore, stimulation of the left TPJ appears to be the ideal control condition for stimulation of the left IFC and it allows a direct contrast between critical nodes of the mentalizing network and AON in the recognition of FAs.

\section{Stimuli and tasks}

In Experiments 2 and 3, participants underwent the same FAD task used in Experiment 1: they were presented with TAs and FAs and had to judge whether the actor was trying to deceive them about the cube's weight (Fig. $1 B$ ). To augment stimulus variability for the behavioral test, we increased the number of recorded clips, weights, and actors. Six nonprofessional actors were thus videotaped while reaching, grasping, lifting, and placing a cube on a shelf. Three visually identical cubes (size, $5 \times 5 \times$ $5 \mathrm{~cm})$ with different weights $(50,350$, or $650 \mathrm{~g})$ were used. Using the same procedure described for Experiment 1, we created new TA and FA clips. Two experimenters initially selected 12 actions for each actor from a pool of $\sim 100$ clips. The selected actions consisted of 6 TAs and 6 FAs: TA stimuli included two different versions of light $(50 \mathrm{~g})$, medium $(350 \mathrm{~g})$, and heavy cubes $(650 \mathrm{~g})$; FA stimuli included two apparently light FAs ( 350 and $650 \mathrm{~g}$ cubes moved as if they weighed $50 \mathrm{~g}$ ), two apparently medium FAs (50 and $650 \mathrm{~g}$ cubes moved as if they weighed $350 \mathrm{~g}$ ), and two apparently heavy FAs (50 and $350 \mathrm{~g}$ cubes moved as if they weighed $650 \mathrm{~g}$ ). A preliminary analysis performed on the temporal duration of lifting and placing (the main kinematic parameter that was found to differentiate visual conditions in Experiment 1) suggested that for each weight appearance, the two FA recordings were not different in terms of variability relative to the two correspondent TA recordings. However, movement duration of FAs was more variable than that of TAs: this was because the pool of FAs included movements that represented an exaggeration of the correspondent TAs (e.g., apparently heavy FAs were slower than heavy TAs and apparently light FAs tended to be faster than light TAs; see also Experiment 1). This suggests that recognition of FAs and TAs in the FAD task may rely on the monitoring of spatiotemporal cues in the observed actions (see Experiment 1 for analyses of additional kinematic parameters differentiating the two classes of action). The 72 clips ( 12 clips $\times 6$ actors) were tested in a psychophysical experiment in which a group of 20 participants ( 10 females; mean age, 22.2 years; range, 20-30 years) performed an FAD task. Based on their performance, we selected a total of 26 clips ( 13 TAs, 13 FAs) from three actors recognized with $\sim 75 \%$ accuracy. In the final sample, for each actor, an equal number of TA and FA clips was shown.

For the FAD task, two types of response were scored as correct: a "yes" response to FAs (hit) and a "no" response to TAs (correct rejection). Two types of response were scored as incorrect: a "yes" response to TAs (false alarm) and a "no" response to FAs (miss). This procedure enabled us to determine task sensitivity $\left(d^{\prime}\right)$ and response criterion (c) indices of the task signal detection method (Green and Swets, 1966).

Kinematic analysis of movies in Experiment 1 suggested that recognition of deceptive body movements mainly relied on the processing of spatiotemporal (e.g., acceleration, movement duration) and configurational (wrist angle) cues differentiating FAs and TAs. To evaluate the specific role of IFC and TPJ in extracting deceptive intents from spatiotemporal and configurational action cues, a spatial control (SC) task not requiring such processing was designed. During the $S C$ task the same set of clips used for the FAD task was presented and subjects had to decide (forced choice) whether a white dot presented for $350 \mathrm{~ms}$ at the end of each clip was located inside or outside the trajectory covered by the hand during the action (Fig. 1C). This task required participants to maintain a global visuospatial representation of the hand path without needing to attend to subtle changes in acceleration or posture/configuration, which are critical to detecting deceptive movements.

For the SC task, two types of response were scored as correct: a "yes" response to dot-on-trajectory (hit) and a "no" response to dot-outsidetrajectory (correct rejection). Two types of response were assigned as incorrect: "yes" response to dot-outside-trajectory (false alarm) and "no" response to dot-on-trajectory (miss). Indices of task sensitivity (d') and criterion $(c)$ were estimated for the SC.

A further psychophysical study (16 subjects; 7 female; mean age, 24.4 years; range, 20-32 years) was run to assess performance in the two tasks. 
Subjects were able to discriminate TAs and FAs in the FAD task ( $d^{\prime}=$ $1.26)$ and to correctly respond to the SC task $\left(d^{\prime}=2.00\right)$. Performance in the SC task appeared nonsignificantly higher than in the FAD task $\left(t_{15}=\right.$ $3.79, p=0.07)$.

In Experiment 3, the SC task was made more difficult by changing the position of the dot only in those trials of Experiment 2 in which accuracy was $90-100 \%$. This procedure was successful in matching the difficulty of the two tasks (see Results).

\section{Neuronavigation}

Coil position was identified on each participant's scalp with the SofTaxic Navigator system (Electro Medical Systems) (Urgesi et al., 2007a,b; Bertini et al., 2010; Serino et al., 2011; Avenanti et al., 2012a). Skull landmarks (nasion, inion, and 2 preauricular points) and $\sim 100$ points providing a uniform representation of the scalp were digitized by means of a Polaris Vicra digitizer (Northern Digital). Coordinates in Talairach space were automatically estimated by the SofTaxic Navigator from an MRI-constructed stereotaxic template (Fig. 1D).

The IFC scalp location that corresponded best to the pars opercularis of the left inferior frontal gyrus (at the border with the ventral premotor cortex) was identified by means of the SofTaxic Navigator system and marked with a pen. On the basis of previous fMRI (Buccino et al., 2004; Costantini et al., 2005; Molnar-Szakacs et al., 2005; Gazzola et al., 2007) and TMS studies (Avenanti et al., 2007, 2012b; Urgesi et al., 2007a,b; Candidi et al., 2008), we targeted the left IFC at the following coordinates $($ mean \pm SEM): $x=-57 \pm 0.4 ; y=+13 \pm 0.3 ; z=+24 \pm 0.3$ (Experiment 2); and $x=-57 \pm 0.2 ; y=+13 \pm 0.2 ; z=+24 \pm 0.1$ (Experiment $3)$. Previous studies have shown that this region is active during action execution and observation (Kilner et al., 2009) and may play a role in action perception (Cattaneo et al., 2010; Avenanti and Urgesi, 2011).

As a control, in Experiment 2 we targeted the scalp location that corresponded best to the TPJ at the following coordinates: $x=-63 \pm 0.2$; $y=-44 \pm 0.4 ; z=+22 \pm 0.2$. The coordinates were chosen based on the study by Grèzes et al., 2004. However, to avoid unwanted effects of hemispheric differences, we selected the site in the left hemisphere. Notably this region is active when reading others' intentions during lying judgments (Harada et al., 2009) and damage to it impairs the understanding of others' intentions (Chiavarino et al., 2010).

Stimulation of IFC and TPJ may cause contraction of facial and temporalis muscle fascia, respectively. To rule out that any differential effect of IFC/TPJ stimulation on performance was simply due to any difference in peripheral sensations, we performed a TMS pilot study on seven subjects ( 3 women; mean age, 25.4 years; range, $20-35$ years) not participating in the main experiments. Each subject received two trains of rTMS over the left IFC and over the left TPJ (randomized order) using the same coordinates and stimulation parameters as used in Experiments 2 and 3. Subjects were asked to report the unpleasantness of the scalp sensation by using a $10 \mathrm{~cm}$ visual analog scale with $0 \mathrm{~cm}$ indicating "no effect" and 10 $\mathrm{cm}$ "maximal effect imaginable." Ratings were low and comparable for the left IFC $(2.37 \pm 1.7)$ and left TPJ stimulations ( $1.83 \pm 0.93 ; t_{7}=0.77$, $p=0.47)$. These findings suggest that peripheral sensations do not likely explain differential behavioral effect due to IFC/TPJ stimulation.

\section{Procedure}

Experiments 2 and 3 were performed with the same apparatus, instruments, and software used in Experiment 1. Before starting the rTMS session, subjects underwent a practical training as described for Experiment 1 (cube lifting). Then the OSP and the individual rMT of the right FDI were determined (Rossini et al., 1994). After neuronavigation, subjects were presented with task instruction and an example of the stimulus presentation timeline. Each subject performed the FAD task and SC task in two separate rTMS sessions presented in a counterbalanced order and separated by a 20 min break. For each task, two blocks of 13 active rTMS trials and two blocks of 13 sham rTMS trials were performed following an ABBA counterbalanced order. Each trial started with a gray screen (duration, $1000 \mathrm{~ms}$ ) followed by the clip (5000 ms). In both tasks (FAD, SC) a white dot at the end of each movie was presented for $350 \mathrm{~ms}$ followed by the response screen (FAD task: "Did the actor try to deceive you?"; SC task: "Was the dot on the hand trajectory?"), which remained active until response by keypress ("Yes/No"). Then, a black screen appeared in the intertrial interval (lasting 8-12 s). In both experiments and tasks, participants were asked to respond as quickly and accurately as possible by keypress, using the index and middle fingers of the left hand (ipsilateral to the stimulation site). On each trial, a time-locked single train of $6 \mathrm{~Hz}$ rTMS (12 pulses, $2 \mathrm{~s}$ ) was delivered when the actor's hand touched the cube (Fig. $1 B, C$ ). The rTMS train covered the entire lifting and placing phase of all clips. Pulse intensity was set at $90 \%$ of rMT. Values of rMT (mean \pm SEM) were comparable across the three groups (IFC Experiment 2: $58 \pm 1.5 \%$; TPJ Experiment 2: $56 \pm 2.9 \%$; IFC Experiment 3: $\left.61 \pm 2.3 \% ; F_{(2,24)}=0.87, p=0.42\right)$.

\section{Data handling}

Behavioral data were processed offline. In Experiments 2 and 3 and in the psychophysical studies, accuracy converted into a measure of sensitivity (MacMillan and Creelman, 1991) was measured for each task (FAD, SC) and rTMS condition (active, sham). Outliers with performance exceeding the sample mean \pm 2 SDs were removed (1 subject from each group in Experiment 2). In Experiment 2, a mixed-model ANOVA was performed on $d^{\prime}, c$, and response time (RT) with Type of rTMS (active, sham) and Task (FAD, SC) as within-subject factors, and Stimulation Site (IFC, TPJ) as a between-subject factor. In Experiment 3, a repeatedmeasure ANOVA was performed with Type of rTMS (active, sham) and Task (FAD, SC) as within-subject factors.

\section{Results}

\section{Experiment 1}

Actor's arm kinematic pattern

Movement duration. The Action Type $\times$ Apparent Weight $\times$ Phase ANOVA on movement duration (expressed in milliseconds) revealed a significant main effect of Phase $\left(F_{(1,4)}=18.42\right.$, $p=0.012$ ), with longer duration for the lifting (mean duration \pm SEM: $610 \pm 50 \mathrm{~ms}$ ) relative to the placing phase $(320 \pm 30 \mathrm{~ms})$, a significant main effect of Action Type and of Apparent Weight (all $F>18.00, p<0.01$ ) and, importantly, an interaction between the two $\left(F_{(1,4)}=128.00, p<0.001\right.$; Fig. $\left.2 A\right)$. Post hoc analysis revealed a longer mean duration for apparently heavy TAs (490 \pm $80 \mathrm{~ms}$ ) than for apparently light TAs ( $420 \pm 40 \mathrm{~ms} ; p=0.001)$; the duration of apparently heavy FAs (580 $\pm 160 \mathrm{~ms})$ was significantly longer than that of apparently heavy TAs $(p<0.001)$, while the duration of apparently light FAs $(380 \pm 60 \mathrm{~ms})$ was shorter than that of apparently light TAs $(p=0.007)$. No other significant interactions were found (all $F<2.17, p>0.22$ ).

Wrist acceleration. The Action Type $\times$ Apparent Weight $\times$ Phase ANOVA on mean acceleration (in centimeters per second squared) of the wrist revealed nonsignificant main effects of Action Type and Apparent Weight $(F<5.54, p>0.078)$, and a significant Action Type $\times$ Apparent Weight interaction $\left(F_{(1,4)}=\right.$ $10.94, p=0.03$; Fig. $2 B$ ) with greater acceleration for apparently light FAs $\left(204.37 \pm 12.35 \mathrm{~cm} / \mathrm{s}^{2}\right)$ relative to the other three conditions (all $<142.41 \pm 14.70 \mathrm{~cm} / \mathrm{s}^{2}$; all comparisons $p<0.046$ ). No other significant main effects or interactions were found (all $F<1.67, p>0.26)$.

An additional Action Type $\times$ Apparent Weight ANOVA performed on wrist acceleration peak (in centimeters per second squared) revealed a marginally significant main effect of Apparent Weight $\left(F_{(1,4)}=6.49, p=0.06\right)$ with greater acceleration peak for apparently light actions $\left(353.83 \pm 33.65 \mathrm{~cm} / \mathrm{s}^{2}\right)$ relative to apparently heavy actions $\left(296.77 \pm 18.74 \mathrm{~cm} / \mathrm{s}^{2}\right.$; Fig. $\left.2 C\right)$. No other main effects or interactions were found (all $F<4.83$, $p>$ $0.09)$.

Grip aperture. The Action Type $\times$ Apparent Weight ANOVA on maximal grip aperture during the reaching phase (in centimeters) showed no significant main effects or interaction (all $F<$ 8.57, $p>0.21$; mean aperture across videos: $9.04 \pm 0.31 \mathrm{~cm})$. 
Similarly, the Action Type $\times$ Apparent Weight ANOVA on grip aperture during the lifting/placing phases (in centimeters) revealed no significant main effects or interactions (all $F<0.34, p>0.66$; mean aperture across videos: $6.17 \pm 0.03 \mathrm{~cm}$ ).

Arm vertical peak. The Action Type $\times$ Apparent Weight ANOVA on arm vertical peak (in centimeters) revealed only the main effect of Action Type $\left(F_{(1,1)}=13.79\right.$, $p=0.02$; Fig. $2 D)$ with higher arm peak height during TAs $(27.70 \pm 0.52 \mathrm{~cm})$ relative to FAs $(25.94 \pm 0.28 \mathrm{~cm})$. No other significant main effects or interactions were found (all $F<2.87, p>0.16$ ).

Wrist angle. The Action Type $\times$ Apparent Weight $\times$ Phase ANOVA on wrist angle degree revealed only the main effect of Action Type $\left(F_{(1,1)}=18.55, p=0.01\right.$; Fig. $2 E)$ with greater wrist angle during FAs $\left(168.46 \pm 1.27^{\circ}\right)$ relative to TAs $\left(162.01 \pm 3.93^{\circ}\right)$. No other significant main effects or interactions were found (all $F<3.77, p>0.12$ ).

In sum, kinematic data suggest that during FAs the actor effectively/successfully modulated the acceleration peak of his arm to deceive the observer. However, the total duration of the FAs was exaggerated relative to that of the correspondent TAs (Brault et al., 2012): lifting and placing in the apparently heavy FAs (i.e., light cube moved as if it was a heavy cube) lasted longer than in the heavy TAs; whereas movements were faster in the apparently light FAs than in the light TAs. As a result, movement duration in the FAs was more variable than in the TAs and in principle observers could monitor such spatiotemporal information to solve the FAD task. Moreover, mean acceleration of the wrist for apparently light (but actually heavy) cubes was greater than for all the other visual conditions both during lifting and placing. In addition, the arm vertical peak was lower and the wrist angle was greater during FAs relative to TAs. Thus, the actor's intention to deceive affected spatiotemporal (mean arm acceleration/duration of lifting and placing) and configurational (maximum wrist angle) but also spatial (arm vertical peak) features of the performed action, and observers could rely on these subtle visual cues to accurately detect the intent to deceive. In contrast, the findings that grip aperture before or during lifting/placing phases was not different in the different conditions and the fact that videos were checked for the absence of changes in skin tone due to hand contraction, suggest that local information about the hand could not be used to perform the FAD task.

\section{EMG activity during action execution}

EMG during execution. Overall, during action execution, the EMG signal increased $207 \%$ with respect to the baseline levels. The Muscle $\times$ Action Type $\times$ Apparent Weight ANOVA performed on EMG ratios revealed a significant main effect of Action Type $\left(F_{(1,9)}=9.35, p=0.014\right)$, a significant Action Type $\times$ Apparent Weight interaction $\left(F_{(1,9)}=28.49\right.$, $p<0.001)$ and, importantly, a significant three-way interaction $\left(F_{(1,9)}=9.05, p=0.015\right)$. To further analyze this inter-

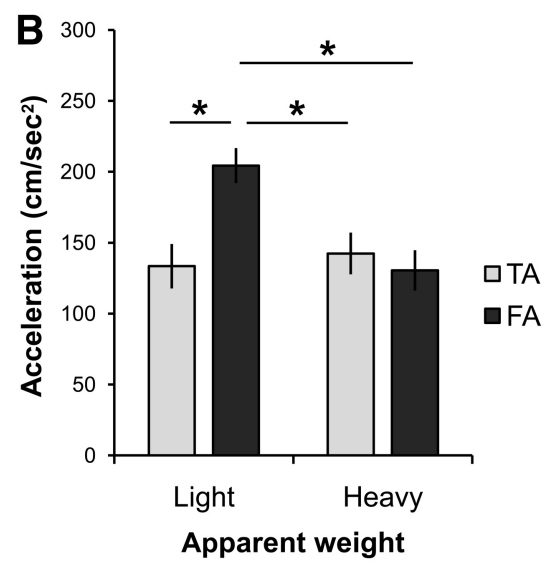

E
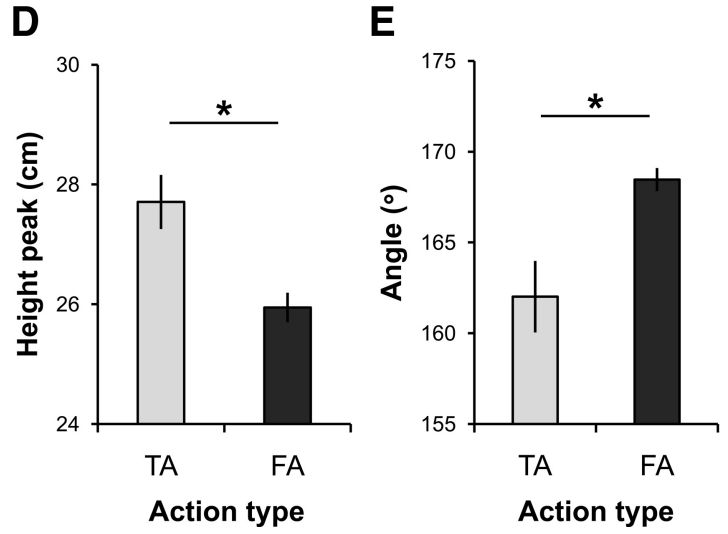

Figure 2. Kinematic parameters of the movements performed by the actor in the FAD movies. $\boldsymbol{A}$, Movement duration. $\boldsymbol{B}$, Mean wrist acceleration. $\boldsymbol{C}$, Wrist acceleration peak. D, Wrist vertical peak. $\boldsymbol{E}$, Wrist angle. Asterisks indicate significant comparisons $(p<$ 0.05). § indicates marginally significant comparisons $(p=0.06)$. Error bars denote SEM.

action, two separate Action Type $\times$ Apparent Weight ANOVAs were carried out, one for each muscle.

The ANOVA performed on the FDI (Fig. $3 A$ ) showed no main effect of Apparent Weight $\left(F_{(1,9)}=0.03, p=0.86\right)$, a significant main effect of Action Type $\left(F_{(1,9)}=32.92, p<\right.$ $0.001)$ and, importantly, a significant two-way interaction $\left(F_{(1,9)}=33.42, p<0.001\right)$. This interaction was entirely driven by the effect of the real weight of the cube: indeed, higher EMG level was found for the two conditions in which a heavy cube was lifted (apparently heavy TA: $207 \pm 14 \%$; and apparently light FA: $236 \pm 12 \%$ ) relative to the two conditions in which a light cube was lifted (apparently light TA: $148 \pm 5 \%$; and apparently heavy FA: $171 \pm 17 \%$; all comparisons $p<0.043$ ). Both the former $(p=0.09)$ and the latter $(p=0.15)$ two conditions did not differ from one another.

The ANOVA performed on the FCR (Fig. 3B) revealed a nonsignificant main effect of Apparent Weight $\left(F_{(1,9)}=1.12\right.$, $p=0.32$ ), a marginally significant main effect of Action Type $\left.F_{(1,9)}=4.43, p=0.065\right)$ and, importantly, a significant two-way interaction $\left(F_{(1,9)}=19.43, p=0.002\right)$. Higher EMG level was found when heavy objects were lifted as if they were light objects (apparently light FA: $271 \pm 26 \%$ ) relative to the other three conditions (all $<218 \pm 21 \% ; p<0.006$ ) which in turn did not differ from one another (all $p>0.18$ ).

$E M G$ background level. A further Muscle $\times$ Action Type $\times$ Apparent Weight ANOVA was performed on background EMG activity in the $100 \mathrm{~ms}$ preceding the go signal. The ANOVA showed a nonsignificant main effect of Muscle $\left(F_{(1,9)}=3.59, p=\right.$ 0.09; FDI: $0.093 \pm 0.002 \mathrm{mV}$; FCR: $0.082 \pm 0.006 \mathrm{mV}$ ), suggest- 
Action execution
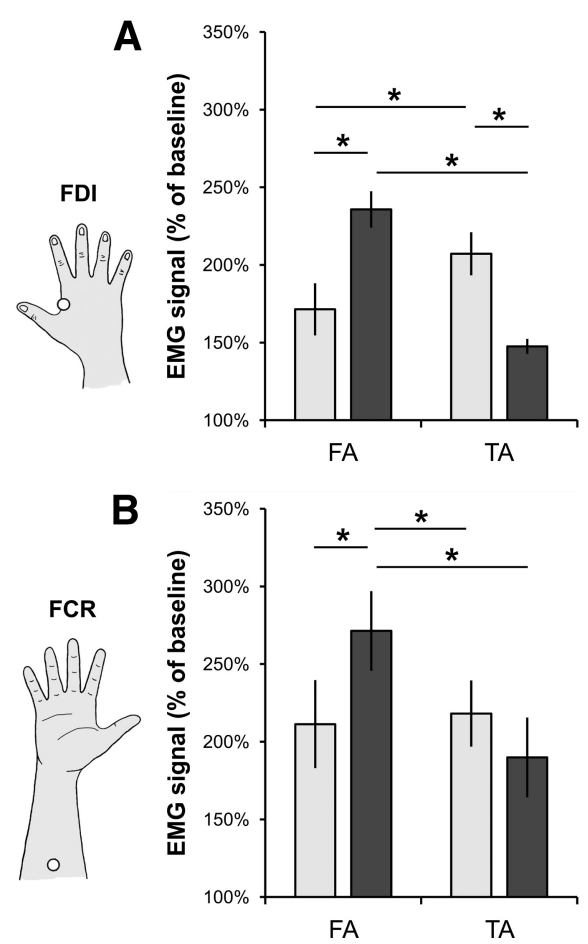
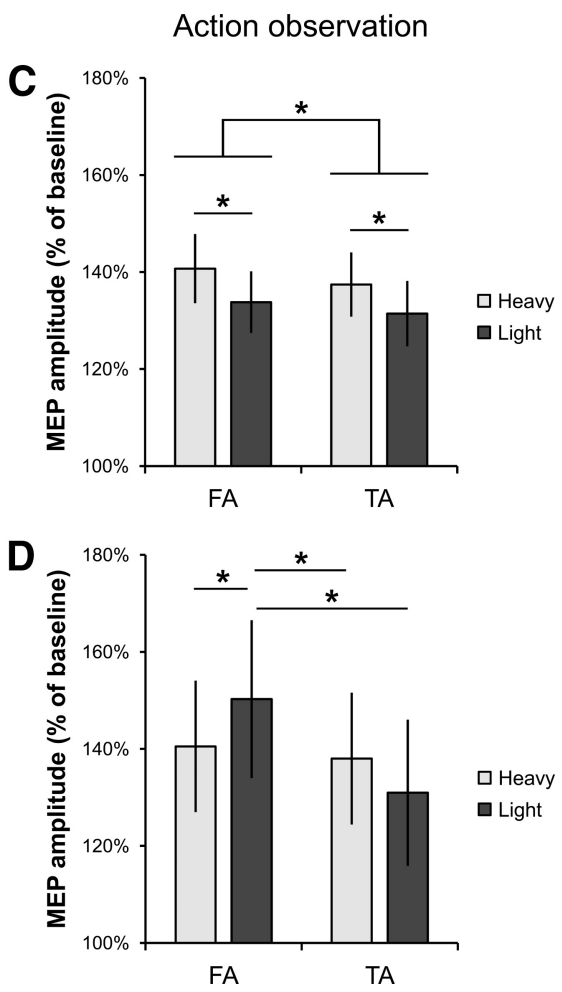

Figure 3. Results from Experiment 1. $\boldsymbol{A}, \boldsymbol{B}$, EMG activity recorded from the $\mathrm{FDI}(\boldsymbol{A})$ and the $F(R(\boldsymbol{B})$ muscles during action execution. $\boldsymbol{C}, \boldsymbol{D}$, MEP amplitudes recorded from the FDI $(\boldsymbol{C})$ and the FCR $(\boldsymbol{D})$ muscles during action observation. Light-gray and dark-gray columns indicate lifting actions with apparently heavy and light cubes respectively. During action execution, activity in the FDI muscle $(\boldsymbol{A})$ was driven by the real weight of the object: greater EMG level was found for heavy (apparently heavy TA; apparently light FA) relative to light cubes (apparently light TA; apparently heavy FA). Activity in the FCR muscle was enhanced when a heavy weight was moved as if it were a light weight $(\boldsymbol{B})$. During action observation, MEPs recorded from the FDI muscle were greater for apparently heavy weight than for light weight and for faked actions (FA) relative to truthful actions (TA) (C). MEPs recorded from the FCR muscle were greater when observing apparently light FAs relative to the other conditions (D). Asterisks indicate significant comparison $(p<0.05)$. Error bars denote SEM.

ing that, during baseline, participants slightly preactivated the FDI muscle, which is critically involved in grasping. Note that this slight contraction during baseline may have underestimated the FDI signal increase during lifting and placing execution (Fig. $3 \mathrm{~A}$, percentage of baseline) relative to the FCR muscle. However, no other main effects or interactions approached significance (all $F<2.44, p>0.15$ ). Thus, the differential pattern of FDI and FCR EMG activity during execution of the different types of motor acts cannot be ascribed to changes in the muscle tension preceding action execution.

In sum, EMG recording revealed that the two muscles differentially contributed to the execution of the different action conditions. The FDI muscle was modulated by the real weight of the cube more than by the specific action type, in keeping with the evidence that hand muscles are critically involved in modulating grip force during lifting (Alaerts et al., 2010a; Senot et al., 2011).

In contrast, the FCR was not modulated by the real weight of the cube during TAs, in line with the notion that FCR is less directly involved in modulating arm force during "normal" (TA) lifting and placing actions (at least when using weights $<2.1 \mathrm{~kg}$ as in Alaerts et al., 2010a,b). The FCR showed increased activity only in the apparently light FAs, reflecting the greater wrist effort and/or postural adjustment associated with lifting a heavy cube as if it were a light cube.

Observers' motor reactivity to actor's actions

MEP data. Overall, during the FAD task, MEP amplitudes increased $138 \%$ with respect to the baseline level. The Muscle $\times$

Action Type $\times$ Apparent Weight ANOVA performed on MEP ratios revealed a main effect of Action Type $\left(F_{(1,13)}=17.96, p<\right.$ $0.001)$, a Muscle $\times$ Action Type interaction $\left(F_{(1,13)}=9.37, p<0.001\right)$, and, importantly, a significant three-way interaction $\left(F_{(1,13)}=9.03, p=0.01\right)$. To further analyze this interaction, two separate Action Type $X$ Apparent Weight ANOVAs were carried out, one for each muscle.

The ANOVA performed on the FDI muscle (Fig. 3C) revealed a main effect of Apparent Weight $\left(F_{(1,13)}=6.22, p=\right.$ 0.03 ) with greater amplitudes during the observation of apparently heavy (139 \pm $6 \%)$ relative to apparently light weights $(132 \pm 6 \%)$. This finding is in keeping with the evidence that observing heavier objects being lifted increases the excitability of the FDI muscle directly involved in the observed action (Alaerts et al., 2010a; Senot et al., 2011). The ANOVA also showed a main effect of Action Type $\left(F_{(1,13)}=5.88, p=0.03\right)$ with greater MEPs recorded during FAs (137 $\pm 6 \%$ ) relative to TAs $(134 \pm 6 \%)$. No interaction between factors was found $\left(F_{(1,13)}=\right.$ 0.07, $p=0.79$ ).

The ANOVA performed on FCR (Fig. 3D) showed no main effect of Apparent Weight $\left(F_{(1,13)}=0.13, p=0.72\right)$ but a main effect of Action Type $\left(F_{(1,13)}=\right.$ 16.13, $p=0.001)$ and, importantly, a significant Action Type $\times$ Apparent Weight interaction $\left(F_{(1,13)}=7.01, p=0.02\right)$. MEPs were greater during observation of heavy objects being lifted as if they were light objects (apparently light FA: $150 \pm 16 \%$ ) relative to the other three conditions (all $<141 \pm 14 \% ; p<0.05)$ which in turn did not differ from one another $(p>0.12)$.

$E M G$ background level. To check whether the observed changes in corticospinal excitability during the FAD task were due to any change in muscle tension, a Muscle $\times$ Action Type $\times$ Apparent Weight ANOVA was performed on background EMG activity in the $100 \mathrm{~ms}$ preceding the TMS pulse. The ANOVA did not show any significant main effects or interactions (all $F<2.74$, $p>0.12$; mean EMG signal: $0.026 \pm 0.001 \mathrm{mV}$ ).

\section{Experiment 1 summary}

In sum, Experiment 1 shows a differential contribution of muscles controlling the hand (FDI) and the wrist (FCR) when lifting and placing objects and, importantly, it highlights the specific involvement of the cortical representation of the two muscles in the simulation of observed FAs/TAs.

During execution, the FDI critically contributed to the control of grip force, with a specific modulation as a function of the actual weight of the cube. By contrast, the FCR was not modulated by the different weights during TAs. However, there was an increase in the FCR activity when a heavy cube was moved as if it were a light cube (apparently light FAs), reflecting the greater wrist involvement during this effortful action.

It should be noted that during action observation there were no apparent local visual cues on the hand signaling the actual 
involvement of the FDI muscle in the different visual conditions. Indeed, kinematic analysis shows that grip aperture (which is controlled by hand muscles, including the FDI) was similar in all the movies. Moreover, no local information about hand-muscle contraction (e.g., changes in skin tones) was present in the different videos. Thus, since heavy and light cubes were also visually identical, during observation, any involvement of the FDI muscle had to be inferred on the basis of global movement parameters (e.g., movement duration). Kinematic analysis suggests that accurate inference of the actual FDI involvement (grip force) required monitoring of the observed actions for their entire duration and integration of both configurational and spatiotemporal cues. On the other hand, kinematic and EMG data suggest that the greater acceleration of the wrist when a heavy cube was moved as if it were a light cube (apparently light FA) could have signaled the greater FCR involvement early. This may suggest that, during observation, FCR MEPs would reflect actual muscle involvement more accurately than FDI MEPs.

Indeed, MEP data show greater FCR facilitation when observing apparently light FAs, thus closely resembling the modulation of the FCR muscle found during action execution.

In contrast, FDI MEPs during action observation did not parallel action execution data. We found that watching apparently light and heavy objects being lifted differentially modulated the excitability of the observers' FDI muscle (Alaerts et al., 2010a; Senot et al., 2011), with greater "resonant" facilitations for apparently heavy than for apparently light objects. Thus, during observation, the cortical motor representation of the FDI muscle was affected by the apparent grip force that could be inferred on the basis of a rough categorization of the observed movement as quick (light weight) or slow (heavy weight). Critically, the hand motor representation was also sensitive to the type of actions being observed. Greater motor excitability was detected in the FDI muscle when watching FAs relative to TAs, indicating that recognition of deceptive movements enhanced the FDI resonant facilitation.

These findings can be interpreted within the framework of predictive theories of action perception (Wilson and Knoblich, 2005; Kilner et al., 2007, 2011; Schütz-Bosbach and Prinz, 2007; Kokal and Keysers, 2010; Schippers and Keysers, 2011; Avenanti et al., 2012b), according to which, understanding of others' actions is mediated by the generative and predictive functions of the AON (Kilner et al., 2004; Avenanti et al., 2009; Urgesi et al., 2010). According to this perspective, during action observation the motor system starts generating a prior expectation about the observed action (e.g., its goal/intention and the associated motor commands). Given this prior expectation, the AON generates a prediction about the sensory consequences of the action (i.e., its expected kinematics). This prediction is then compared with the actual sensory information and prediction errors arising from that comparison are returned to the higher level to adjust the initial prediction (Kilner, 2011; Press et al., 2011).

On the basis of this framework, we posit that during the FAD task, changes in motor excitability reflected a weighted combination of prior predictions generated in the motor system and prediction error signals returning to the motor system. The pattern of FCR and FDI MEPs can be promptly accounted for within this framework. After motor training with the cubes and visual exposure to the actor's movies in the initial phases of the task, participants may have learned that actions starting with larger mean wrist acceleration (apparently light FAs) are likely to use the FCR muscle to a greater extent and would result in more observed wrist movement. Hence, during the MEP recording phase of the
FAD task, seeing actions starting with larger wrist acceleration may have generated the prediction of a greater FCR involvement, which was reflected in an increased excitability of the FCR motor representation. In these conditions, the AON would predict greater observed wrist involvement (Kilner, 2011; Press et al., 2011). Because of the close correspondence between the predicted (prior) and the observed actions, it is likely that excitability of the FCR muscle reflected mainly the prior prediction and little prediction error. This may explain the similarity between MEPs during action observation and EMG during action execution.

For the FDI muscle, the MEPs did not correspond so closely to the EMG data, likely because kinematic cues signaling the possible involvement of the index finger were more ambiguous in the initial phases of the movement. It is plausible that changes in FDI MEPs reflected both aspects of the prior prediction and the prediction error. When observing TAs, changes in FDI excitability (greater MEP for heavy than for light TAs) mainly reflected the prior prediction (greater index finger involvement for heavy than for light cubes) and little prediction error. When seeing FAs, changes in FDI excitability reflected the (inaccurate) prior prediction that was likely based on initial kinematic cues. As soon as sensory information violating the expected kinematics was available, a (facilitatory) prediction error signal arising from that comparison returned to the motor system and affected the cortical representation of the FDI, leading to a further increase in FDI motor excitability. This error signal may have been used to adjust the prior prediction and recognize the deceptive intent in the actor.

These findings indicate that (1) violation of predicted actions specifically modulates motor resonance processes with a high degree of muscle specificity; and (2) different sectors of the motor system dynamically map kinematic features of observed actions, with differential coding for apparently light and heavy weight lifting, and for FAs and TAs.

\section{Experiment 2}

Results from Experiment 1 confirm the notion that watching right-hand actions increases the excitability of the observer's left motor cortex (Fadiga et al., 1995; Aziz-Zadeh et al., 2002; SchützBosbach et al., 2009; Borgomaneri et al., 2012), an effect that is likely mediated by activity in the left IFC (Avenanti et al., 2007, 2012b; Catmur et al., 2011; Koch et al., 2010), the human homolog region of the monkey ventral premotor cortex, where mirror neurons have been discovered (di Pellegrino et al., 1992; Gallese et al., 1996). We found that observers' corticospinal system was sensitive to the apparent weight of observed objects being lifted (i.e., predicted on the basis of internal models of action) (Alaerts et al., 2010a,b; Senot et al., 2011) and conveyed information about the possible violation of the predicted action (during FAs). These findings clearly demonstrate that FAD specifically affects action simulation in the motor system. However, they do not establish whether the $\mathrm{AON}$ is also necessary for performing FAD. To test whether the AON plays an essential role in visual recognition of FAs and TAs, a second experiment was performed using online rTMS during the execution of the FAD task. The AON was targeted in its anterior node, namely the left IFC, and as an active control site we stimulated a key region within the mentalizing network, namely the left TPJ. This way we contrasted the possible involvement of simulative (in IFC) and mentalizing (in TPJ) processing in FAD.

Notably, Experiment 1 suggested that spatiotemporal (e.g., acceleration) and configurational (wrist angle) features of seen actions are critical to discriminating FAs and TAs and thus rec- 

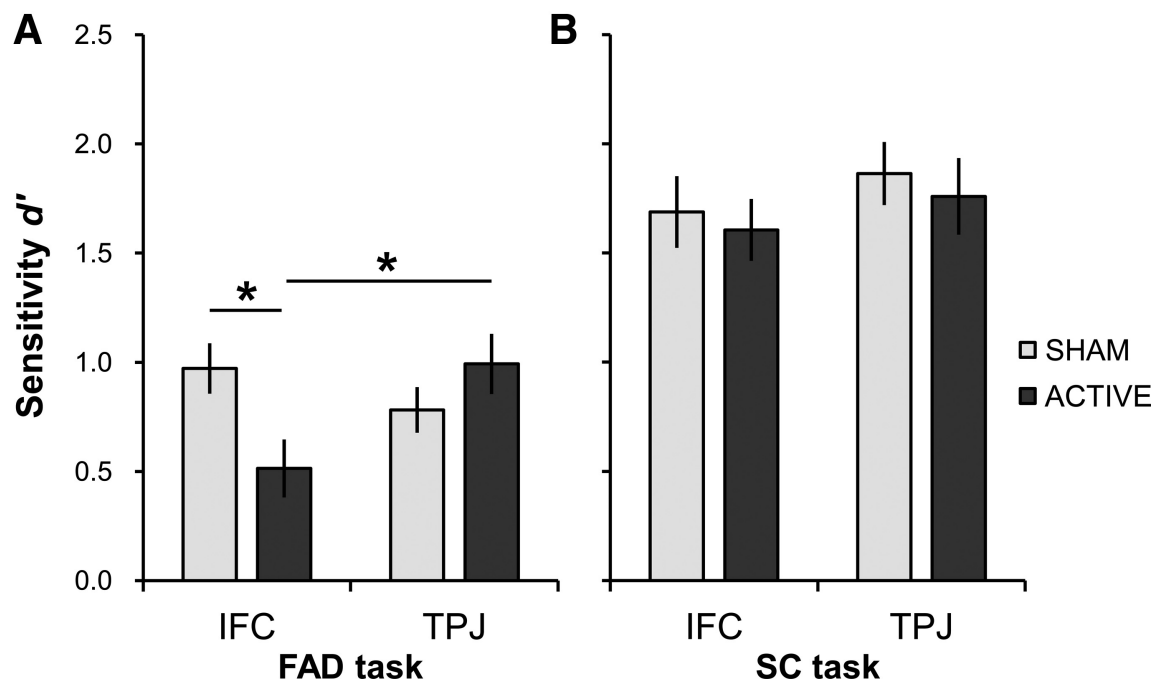

Figure 4. $\boldsymbol{A}, \boldsymbol{B}$, Mean sensitivity $\left(d^{\prime}\right)$ in the FAD task $(\boldsymbol{A})$ and SC task $(\boldsymbol{B})$ of Experiment 2. Light-gray and dark-gray columns represent sham rTMS and active rTMS respectively. Active rTMS over IFC reduced sensitivity in the FAD task $(\boldsymbol{A})$. No change in sensitivity due to rTMS was observed in the SC task $(\boldsymbol{B})$. Asterisks indicate significant comparisons $(p<0.05)$. Error bars denote SEM.

ognition of deceptive intents may require monitoring of such action cues. To check for unspecific effects of rTMS, we tested participants in an SC task that required monitoring of spatial features of seen actions (hand trajectory), but not to read others' intentions based on spatiotemporal/configurational cues.

The Task $\times$ Type of rTMS $\times$ Stimulation Site ANOVA performed on the index of sensitivity ( $d$ ') revealed a main effect of Task $\left(F_{(1,26)}=56.76, p<0.001\right)$ accounted for by higher accuracy in the SC task (mean $d^{\prime} \pm$ SEM: $1.73 \pm 0.46$ ) than in the FAD task $(0.81 \pm 0.21)$. Importantly, a significant three-way interaction was found $\left(F_{(1,26)}=5.25, p=0.03\right)$. To further analyze this interaction, two separate Type of rTMS $\times$ Stimulation Site ANOVAs were carried out, one for each task.

The ANOVA performed on $d$ ' computed from FAD task performance showed a significant two-way interaction $\left(F_{(1,26)}=\right.$ 7.52, $p=0.01$; Fig. 4). Post hoc analysis indicates that the interaction was accounted for by lower sensitivity in the IFC group during active rTMS $(0.51 \pm 0.13)$ compared with sham rTMS $(0.97 \pm 0.26 ; p=0.03)$ and active rTMS in the TPJ group $(0.99 \pm$ $0.26 ; p=0.04)$. No change in performance due to rTMS was found in the TPJ group ( $p=0.45)$.

The Type of rTMS $\times$ Stimulation Site ANOVA performed on $d$ ' computed from SC task performance showed no main effects or interactions (all $F<0.73, p>0.40$ ).

The Task $\times$ Type of rTMS $\times$ Stimulation Site ANOVA performed on the response criterion $(c)$ revealed no main effects or interactions (all $F<2.56, p>0.12$; Table 1). The Task $\times$ Type of rTMS $\times$ Stimulation Site ANOVA performed on RTs showed only a nonsignificant main effect of Task $\left(F_{(1,26)}=3.04, p=0.09\right)$, with slightly faster responses in the SC task (mean RT \pm SEM: $657 \pm 175 \mathrm{~ms}$ ) compared with the FAD task (751 $\pm 201 \mathrm{~ms})$. No other main effect or interactions (all $F<1.38, p>0.25$ ) approached statistical significance (Table 1).

In sum, interference with left IFC, but not with left TPJ, impaired performance in the FAD task, suggesting that action simulation processes in IFC may be fundamental for visual discrimination of FAs and TAs. Because these two visual conditions shared the same apparent goal (lifting/placing), but differed in terms of spatiotemporal (e.g., variability of movement duration, mean acceleration peak) and configurational (e.g., maximum wrist angle) features, the suggestion is made that IFC is critically involved in the processing of kinematic cues necessary for inferring deceit from observed actions. No detrimental effects of IFC-rTMS were found in the SC task requiring simple processing of the spatial features of seen actions. However, the SC task was easier than the FAD task. To rule out that the differential effect of IFCrTMS in the two tasks was simply due to a ceiling effect, we performed a third rTMS experiment, in which FAD and SC tasks were matched for difficulty.

\section{Experiment 3}

The Task $\times$ Type of rTMS ANOVA performed on $d$ ' revealed a significant interaction $\left(F_{(1,14)}=5.49, p=0.03\right.$; Fig. 5) accounted for by lower performance in the FAD task during active rTMS $(0.93 \pm$ $0.24)$ compared with sham rTMS $(1.39 \pm 0.36 ; p=0.006)$ and compared with SC task performance during active rTMS (1.42 \pm $0.36 ; p=0.01)$ and sham rTMS conditions $(1.40 \pm 0.36 ; p=$ 0.02 ). By contrast, no change in performance due to rTMS was found in the SC task $(p=0.89)$ and no main effects of Task or Type of rTMS were found (all $F<2.11, p>0.17$ ).

The Task $\times$ Type of rTMS ANOVAs performed on $c$ (all $F<$ $2.70, p>0.122$ ) and RTs (all $F<1.00, p>0.33$ ) showed no main effects or interaction (Table 2).

\section{Discussion}

Action simulation and nonmotor inferential (i.e., mentalistic) processes have often been conceptualized as mutually exclusive. However, recent theoretical (Keysers and Gazzola, 2007; Uddin et al., 2007) and empirical (Brass et al., 2007; de Lange et al., 2008; Schippers et al., 2009; Spunt et al., 2011) work suggests that simulation and mentalizing may have complementary roles in social cognition. Therefore, a central aim of cognitive neuroscience is to clarify the circumstances in which these processes are critical for understanding others' behavior (Mitchell, 2008, 2009). In the present study, we provide correlational and causative evidence that action simulation is called into play when detecting deceptive intents in the body movements of others.

In Experiment 1, we used single-pulse TMS to test whether motor resonance is modulated during discrimination of FAs and TAs (FAD task). We found that watching an actor lifting and placing objects facilitated the observers' motor system (Fadiga et al., 2005), with greater muscle-specific facilitations for apparently heavier weights (Alaerts et al., 2010a). Importantly, processing of FAs strongly facilitated the motor system in a muscle-specific manner, suggesting that action simulation is sensitive to deceptive movements. To test whether action simulation is also required for FA recognition, in Experiment 2 we applied rTMS over the anterior node of the AON (the left IFC) during performance of the FAD task and a control task. As a further control, we applied rTMS over a key node of the mentalizing network, namely the left TPJ. We found that IFC-rTMS but not TPJ-rTMS impaired FAD task (but not control task) performance. In Experiment 3, we replicated this selective detrimental effect. These 
Table 1. Response time and criterion (mean \pm SEM) data collected in Experiment 2

\begin{tabular}{|c|c|c|c|c|c|c|c|c|}
\hline \multirow[b]{2}{*}{ rTMS } & \multicolumn{2}{|l|}{ IFC FAD task } & \multicolumn{2}{|l|}{ IFC SC task } & \multicolumn{2}{|l|}{ TPJ FAD task } & \multicolumn{2}{|l|}{ TPJ SC task } \\
\hline & Sham & Active & Sham & Active & Sham & Active & Sham & Active \\
\hline Criterion (c) & $0.20 \pm 0.05$ & $0.26 \pm 0.07$ & $0.13 \pm 0.10$ & $0.04 \pm 0.13$ & $0.12 \pm 0.06$ & $0.19 \pm 0.10$ & $0.24 \pm 0.10$ & $0.26 \pm 0.12$ \\
\hline RT (ms) & $791 \pm 76$ & $794 \pm 89$ & $718 \pm 61$ & $712 \pm 71$ & $722 \pm 117$ & $700 \pm 120$ & $621 \pm 89$ & $578 \pm 93$ \\
\hline
\end{tabular}

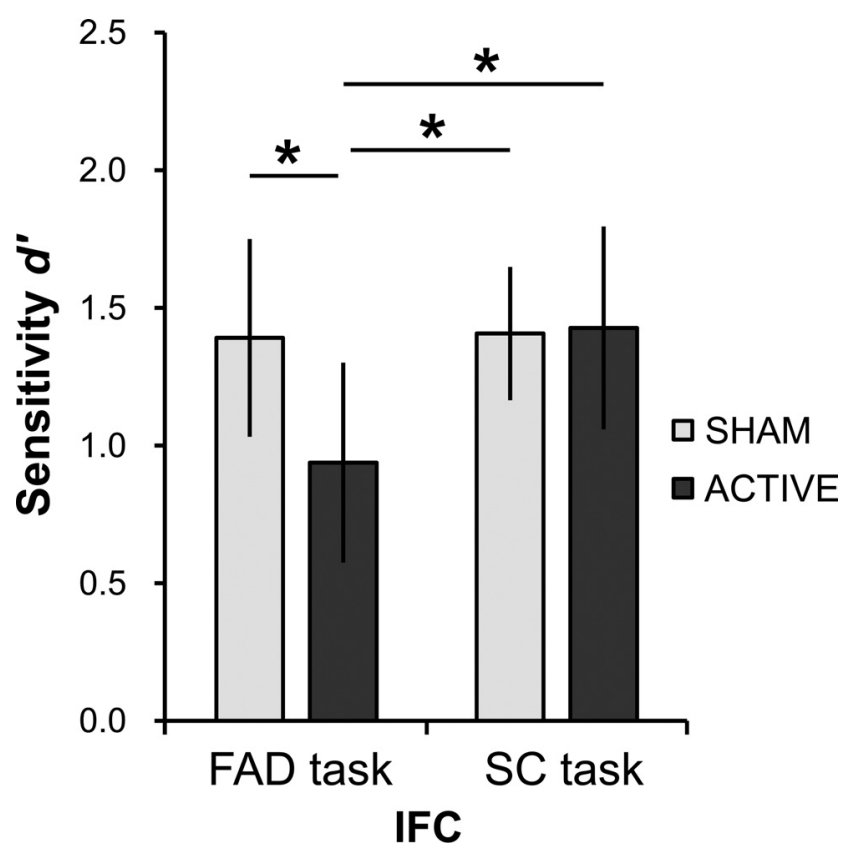

Figure 5. Mean sensitivity ( $\left({ }^{\prime}\right)$ in the FAD and SC tasks of Experiment 3. Light-gray and dark-gray columns represent sham and active rTMS, respectively. Active rTMS over IFC reduced sensitivity in the FAD task but not in the SC task. Asterisks indicate significant comparisons ( $p<$ 0.05). Error bars denote SEM.

Table 2. Response time and criterion (mean \pm SEM) data collected in Experiment 3

\begin{tabular}{llllll}
\hline & IFC FAD task & & & IFC SC task & \\
\cline { 2 - 3 } rTMS & Sham & Active & & Sham & Active \\
\hline Criterion (c) & $0.34 \pm 0.09$ & $0.30 \pm 0.08$ & & $0.20 \pm 0.05$ & $0.32 \pm 0.08$ \\
RT (ms) & $583 \pm 151$ & $580 \pm 150$ & & $635 \pm 164$ & $596 \pm 154$ \\
\hline
\end{tabular}

findings strongly demonstrate that action simulation is critical for inferring deceits from observed kinematics.

\section{Perceiving FAs affect motor resonance}

People can easily identify deceptive intents from observed behavior on the basis of stored internal models of the observed action (Runeson and Frykholm, 1983). It is held that FA recognition relies on the reading of kinematic cues that violate observers' predictions of the ongoing observed action (Bond et al., 1992; Frank and Ekman, 1997). Acquisition of internal action models through motor experience strengthens simulative activity in the motor system (Calvo-Merino et al., 2006; Cross et al., 2006; Fourkas et al., 2008) and improves the ability to read others' action kinematics (Casile and Giese, 2006; Aglioti et al., 2008). Notably, athletes present a superior ability to recognize FAs in their sport domain (Jackson et al., 2006; Sebanz and Shiffrar, 2009). Together, these studies suggest a link between action simulation and the ability to infer deceptive intents from observed kinematics. Results from Experiment 1 provide the first neural evidence for this link by showing specific modulation of motor resonance during FA recognition.
During execution, we found that the target FDI muscle critically contributed to the motor control of lifting and placing and was modulated as a function of the real weight of the cube, suggesting that internal models of lifting/placing may encode grip force and thus FDI involvement. During action observation, FDI MEPs were larger for apparently heavy than for apparently light cubes. This suggests that the motor cortex was modulated by the apparent grip force that could be predicted on the basis of a coarse categorization of the observed movement as quick or slow (suggesting light or heavy weights, respectively; Alaerts et al., 2010b). Notably however, MEPs were also larger for FAs relative to TAs, indicating that processing of subtle kinematic cues violating the predicted actions (and revealing the deceptive intent) was associated with an additional facilitation of the FDI representation. Greater facilitation was not simply due to a semantic coding of, or arousal responses to, FAs, as evidenced by the different modulation detected in the FCR control muscle (see Results).

In keeping with predictive theories of action perception (Wilson and Knoblich, 2005; Kilner, 2011), we suggest that during $\mathrm{FAD}$, the motor system generates an initial prediction about the action and its expected kinematics. This prior prediction is then compared with the incoming sensory input. When a violation of the predicted action is detected (FAs), a prediction error signal reaches those motor representations (e.g., FDI) whose predicted activity did not match the actual seen kinematics. Processing these violations may be functionally akin to the detection of an error in the action plan. In keeping with this idea, studies indicate that watching erroneous actions increases premotor and motor cortex activity (Manthey et al., 2003; van Schie et al., 2004; Koelewijn et al., 2008). Moreover, basketball players watching inaccurate shots at a basket show increase of motor facilitation relative to watching accurate shots (Aglioti et al., 2008). Our study expands this body of evidence by suggesting that during $\mathrm{FAD}$, both prior predictions and their violations are encoded in the corticospinal system with a high degree of topographic specificity. Experiments 2 and 3 highlight the IFC as the possible neural locus where these processes occur and establish its critical role in visual recognition of FAs.

\section{Virtual lesion to IFC impairs deceptive actions recognition}

In Experiment 2, we selected two key regions within the AON and mentalizing networks (left IFC and left TPJ), and applied online rTMS to test their causative role in FAD. We found that IFC-rTMS but not TPJ-rTMS reduced perceptual sensitivity in the FAD task. No change was found in the SC task, suggesting that reduction in performance in the FAD task was not due to unspecific effect of IFC-rTMS. However, the SC task was easier than the FAD task. We thus matched task difficulty and performed a third experiment in which rTMS was again applied to IFC. Results from Experiment 3 replicated the selective FAD task impairment.

These findings provide the first evidence that IFC is critical for inferring deceit from observed kinematics. Previous research has suggested that activity in IFC is sensitive to action goals (Gazzola et al., 2007; Thioux et al., 2008) and intentions (Iacoboni et al., 2005; Liepelt et al., 2008), but also to action kinematics (Hesse et 
al., 2009; Majdandzic et al., 2009), suggesting that IFC may contain multiple action representations. Importantly, recent investigations have started to show that IFC is necessary for action understanding (Moro et al., 2008; Pazzaglia et al., 2008; Avenanti and Urgesi, 2011). In a relevant study, Pobric and Hamilton (2006) demonstrated that IFC is required to estimate the weight of objects from the observation of lifting actions. In that study, IFC-rTMS but not occipital-rTMS reduced accuracy in the weight-judgment task, but not in a pure "temporal" control task requiring participants to estimate how long the hand was visible in the movies. These findings suggested that IFC was necessary for visual processing of action kinematics rather than for a simple evaluation of temporal information. However, RTs were not collected and the control tasks were clearly easier than the main task. Therefore, speed-accuracy trade-off or ceiling effects could not be excluded.

Our study provides causative evidence that the IFC is not only sensitive to action kinematics and intentionality but is also critical for inferring deceit from observed kinematics. By using signal detection theory analysis we demonstrated that IFC-rTMS (but not TPJ-rTMS) reduces perceptual sensitivity but not response bias, demonstrating a clear reduction in the ability to discriminate FAs and TAs. Moreover, IFC-rTMS did not impair performance in the SC task, which required maintenance of a visuospatial representation of the hand path without the necessity to process spatiotemporal (e.g., acceleration) or configurational (e.g., wrist angle) cues critical for FAD. Importantly, the detrimental effect of IFC-rTMS in the FAD task but not in the SC task was not due to a ceiling effect. Moreover, the analysis of RTs rules out that detrimental effects of rTMS were due to a speedaccuracy trade-off.

These findings highlight the specific contribution of the anterior note of the AON to action perception. Left IFC appears critical for visual discrimination of actions that differ in complex configurational and spatiotemporal features rather than in simple visuospatial (e.g., trajectory) or temporal (as suggested by Pobric and Hamilton, 2006) features of seen actions.

In sum, Experiments 1-3 suggest that the analysis of action dynamics performed in the motor system is critical to detecting deceit in the actions of others.

\section{Simulation versus mentalizing in FA recognition}

It has been suggested that judging deceptive actions involves two phases: (1) recognition of cues in behavior that violate the observer's predictions; and (2) drawing inferences about intention on this basis (Bond et al., 1992; Frank and Ekman, 1997). The possible involvement of mentalizing in the recognition of deceits is consistent with the activation of the left TPJ when processing intentions during lying judgments (Harada et al., 2009). This region is active when reflecting on others' beliefs and intentions (Saxe and Powell, 2006; Young et al., 2011) and its lesioning impairs the understanding of these mental states in others (Samson et al., 2004; Chiavarino et al., 2010). Nonetheless, our data suggest that TPJ is less involved than IFC in FA recognition. This may suggest that (at least in the left hemisphere) inferential and mentalizing processes may be epiphenomenal to the detection of deceits from observed body movements, which critically relies on action simulation implemented in the human AON.

\section{References}

Aglioti SM, Cesari P, Romani M, Urgesi C (2008) Action anticipation and motor resonance in elite basketball players. Nat Neurosci 11:1109-1116. CrossRef Medline
Alaerts K, Senot P, Swinnen SP, Craighero L, Wenderoth N, Fadiga L (2010a) Force requirements of observed object lifting are encoded by the observer's motor system: a TMS study. Eur J Neurosci 31:1144-1153. CrossRef Medline

Alaerts K, Swinnen SP, Wenderoth N (2010b) Observing how others lift light or heavy objects: which visual cues mediate the encoding of muscular force in the primary motor cortex? Neuropsychologia 48:2082-2090. CrossRef Medline

Apperly IA, Samson D, Chiavarino C, Humphreys GW (2004) Frontal and temporo-parietal lobe contributions to theory of mind: neuropsychological evidence from a false-belief task with reduced language and executive demands. J Cogn Neurosci 16:1773-1784. CrossRef Medline

Avenanti A, Urgesi C (2011) Understanding "what" others do: mirror mechanisms play a crucial role in action perception. Soc Cogn Affect Neurosci 6:257-259. CrossRef Medline

Avenanti A, Bolognini N, Maravita A, Aglioti SM (2007) Somatic and motor components of action simulation. Curr Biol 17:2129-2135. CrossRef Medline

Avenanti A, Minio-Paluello I, Sforza A, Aglioti SM (2009) Freezing or escaping? Opposite modulations of empathic reactivity to the pain of others. Cortex 45:1072-1077. CrossRef Medline

Avenanti A, Annela L, Serino A (2012a) Suppression of premotor cortex disrupts motor coding of peripersonal space. Neuroimage 63:281-288. CrossRef Medline

Avenanti A, Annella L, Candidi M, Urgesi C, Aglioti SM (2012b) Compensatory plasticity in the action observation network: virtual lesions of STS enhance anticipatory simulation of seen actions. Cereb Cortex. Advance online publication. Retrieved March 16, 2012. doi:10.1093/cercor/ bhs040. CrossRef Medline

Aziz-Zadeh L, Maeda F, Zaidel E, Mazziotta J, Iacoboni M (2002) Lateralization in motor facilitation during action observation: a TMS study. Exp Brain Res 144:127-131. CrossRef Medline

Becchio C, Manera V, Sartori L, Cavallo A, Castiello U (2012) Grasping intentions: from thought experiments to empirical evidence. Front Hum Neurosci 6:117. CrossRef Medline

Bertini C, Leo F, Avenanti A, Làdavas E (2010) Independent mechanisms for ventriloquism and multisensory integration as revealed by theta-burst stimulation. Eur J Neurosci 31:1791-1799. CrossRef Medline

Bond CF Jr, Omar A, Pitre U, Lashley BR, Skaggs LM, Kirk CT (1992) Fishylooking liars: deception judgment from expectancy violation. J Pers Soc Psychol 63:969-977. CrossRef Medline

Borgomaneri S, Gazzola V, Avenanti A (2012) Motor mapping of implied actions during perception of emotional body language. Brain Stimul 5:70-76. CrossRef Medline

Borroni P, Montagna M, Cerri G, Baldissera F (2005) Cyclic time course of motor excitability modulation during the observation of a cyclic hand movement. Brain Res 1065:115-124. CrossRef Medline

Brasil-Neto JP, Cohen LG, Panizza M, Nilsson J, Roth BJ, Hallett M (1992) Optimal focal transcranial magnetic activation of the human motor cortex: effects of coil orientation, shape of the induced current pulse, and stimulus intensity. J Clin Neurophysiol 9:132-136. CrossRef Medline

Brass M, Schmitt RM, Spengler S, Gergely G (2007) Investigating action understanding: inferential processes versus action simulation. Curr Biol 17:2117-2121. CrossRef Medline

Brault S, Bideau B, Kulpa R, Craig CM (2012) Detecting deception in movement: the case of the side-step in rugby. PLoS One 7:e37494. CrossRef Medline

Briggs GG, Nebes RD (1975) Patterns of hand preference in a student population. Cortex 11:230-238. Medline

Buccino G, Lui F, Canessa N, Patteri I, Lagravinese G, Benuzzi F, Porro CA, Rizzolatti G (2004) Neural circuits involved in the recognition of actions performed by nonconspecifics: an fMRI study. J Cogn Neurosci 16:114126. CrossRef Medline

Cabinio M, Blasi V, Borroni P, Montagna M, Iadanza A, Falini A, Cerri G (2010) The shape of motor resonance: right- or left-handed? Neuroimage 51:313-323. CrossRef Medline

Calvo-Merino B, Grèzes J, Glaser DE, Passingham RE, Haggard P (2006) Seeing or doing? Influence of visual and motor familiarity in action observation. Curr Biol 16:1905-1910. CrossRef Medline

Candidi M, Urgesi C, Ionta S, Aglioti SM (2008) Virtual lesion of ventral premotor cortex impairs visual perception of biomechanically possible but not impossible actions. Soc Neurosci 3:388-400. CrossRef Medline 
Casile A, Giese MA (2006) Nonvisual motor training influences biological motion perception. Curr Biol 16:69-74. CrossRef Medline

Catmur C, Mars RB, Rushworth MF, Heyes C (2011) Making mirrors: premotor cortex stimulation enhances mirror and counter-mirror motor facilitation. J Cogn Neurosci 23:2352-2362. CrossRef Medline

Cattaneo L, Sandrini M, Schwarzbach J (2010) State-dependent TMS reveals a hierarchical representation of observed acts in the temporal, parietal, and premotor cortices. Cereb Cortex 20:2252-2258. CrossRef Medline

Chen R, Classen J, Gerloff C, Celnik P, Wassermann EM, Hallett M, Cohen LG (1997) Depression of motor cortex excitability by low-frequency transcranial magnetic stimulation. Neurology 48:1398-1403. CrossRef Medline

Chiavarino C, Apperly IA, Humphreys GW (2010) Distinguishing intentions from desires: contributions of the frontal and parietal lobes. Cognition 117:203-216. CrossRef Medline

Ciaramidaro A, Adenzato M, Enrici I, Erk S, Pia L, Bara BG, Walter H (2007) The intentional network: how the brain reads varieties of intentions. Neuropsychologia 45:3105-3113. CrossRef Medline

Costantini M, Galati G, Ferretti A, Caulo M, Tartaro A, Romani GL, Aglioti SM (2005) Neural systems underlying observation of humanly impossible movements: an FMRI study. Cereb Cortex 15:1761-1767. CrossRef Medline

Cross ES, Hamilton AF, Grafton ST (2006) Building a motor simulation de novo: observation of dance by dancers. Neuroimage 31:1257-1267. CrossRef Medline

de Lange FP, Spronk M, Willems RM, Toni I, Bekkering H (2008) Complementary systems for understanding action intentions. Curr Biol 18:454457. CrossRef Medline

Di Lazzaro V, Oliviero A, Profice P, Saturno E, Pilato F, Insola A, Mazzone P, Tonali P, Rothwell JC (1998) Comparison of descending volleys evoked by transcranial magnetic and electric stimulation in conscious humans. Electroencephalogr Clin Neurophysiol 9:397-401. Medline

di Pellegrino G, Fadiga L, Fogassi L, Gallese V, Rizzolatti G (1992) Understanding motor events: a neurophysiological study. Exp Brain Res 91: 176-180. Medline

Ekman P, O'Sullivan M (1991) Who can catch a liar? Am Psychol 46:913920. CrossRef Medline

Fadiga L, Fogassi L, Pavesi G, Rizzolatti G (1995) Motor facilitation during action observation: a magnetic stimulation study. J Neurophysiol 73: 2608-2611. Medline

Fadiga L, Craighero L, Olivier E (2005) Human motor cortex excitability during the perception of others' action. Curr Opin Neurobiol 15:213218. CrossRef Medline

Fourkas AD, Bonavolontà V, Avenanti A, Aglioti SM (2008) Kinesthetic imagery and tool-specific modulation of corticospinal representations in expert tennis players. Cereb Cortex 18:2382-2390. CrossRef Medline

Frank MG, Ekman P (1997) The ability to detect deceit generalizes across different types of high-stake lies. J Pers Soc Psychol 72:1429-1439. CrossRef Medline

Frith CD, Frith U (2006) The neural basis of mentalizing. Neuron 50:531534. CrossRef Medline

Gallese V, Fadiga L, Fogassi L, Rizzolatti G (1996) Action recognition in the premotor cortex. Brain 119:593-609. CrossRef Medline

Gazzola V, Keysers C (2009) The observation and execution of actions share motor and somatosensory voxels in all tested subjects: single-subject analyses of unsmoothed fMRI data. Cereb Cortex 19:1239-1255. CrossRef Medline

Gazzola V, van der Worp H, Mulder T, Wicker B, Rizzolatti G, Keysers C (2007) Aplasics born without hands mirror the goal of hand actions with their feet. Curr Biol 17:1235-1240. CrossRef Medline

Green DM, Swets JA (1966) Signal detection theory and psychophysics. New York: Wiley.

Grèzes J, Frith C, Passingham RE (2004) Brain mechanisms for inferring deceit in the actions of others. J Neurosci 24:5500-5505. CrossRef Medline

Harada T, Itakura S, Xu F, Lee K, Nakashita S, Saito DN, Sadato N (2009) Neural correlates of the judgment of lying: A functional magnetic resonance imaging study. Neurosci Res 63:24-34. CrossRef Medline

Hesse MD, Sparing R, Fink GR (2009) End or means? The "what" and "how" of observed intentional actions. J Cogn Neurosci 21:776-790. CrossRef Medline
Iacoboni M, Molnar-Szakacs I, Gallese V, Buccino G, Mazziotta JC, Rizzolatti G (2005) Grasping the intentions of others with one's own mirror neuron system. PLoS Biol 3:1-7. CrossRef Medline

Jackson RC, Warren S, Abernethy B (2006) Anticipation skill and susceptibility to deceptive movement. Acta Psychol 123:355-371. CrossRef Medline

Keysers C, Gazzola V (2007) Integrating simulation and theory of mind: from self to social cognition. Trends Cogn Sci 11:194-196. CrossRef Medline

Kilner JM (2011) More than one pathway to action understanding. Trends Cogn Sci 15:352-357. CrossRef Medline

Kilner JM, Vargas C, Duval S, Blakemore SJ, Sirigu A (2004) Motor activation prior to observation of a predicted movement. Nat Neurosci 7:1299_ 1301. CrossRef Medline

Kilner JM, Friston KJ, Frith CD (2007) Predictive coding: an account of the mirror neuron system. Cogn Process 8:159-166. CrossRef Medline

Kilner JM, Neal A, Weiskopf N, Friston KJ, Frith CD (2009) Evidence of mirror neurons in human inferior frontal gyrus. J Neurosci 29:1015310159. CrossRef Medline

Koch G, Versace V, Bonnì S, Lupo F, Lo Gerfo E, Oliveri M, Caltagirone C (2010) Resonance of cortico-cortical connections of the motor system with the observation of goal directed grasping movements. Neuropsychologia 48:3513-3520. CrossRef Medline

Koelewijn T, van Schie HT, Bekkering H, Oostenveld R, Jensen O (2008) Motor-cortical beta oscillations are modulated by correctness of observed action. Neuroimage 40:767-775. CrossRef Medline

Kokal I, Keysers C (2010) Granger causality mapping during joint actions reveals evidence for forward models that could overcome sensory-motor delays. PLoS ONE 5:e13507. CrossRef Medline

Liepelt R, Von Cramon DY, Brass M (2008) How do we infer others' goals from non-stereotypic actions? The outcome of context-sensitive inferential processing in right inferior parietal and posterior temporal cortex. Neuroimage 43:784-792. CrossRef Medline

Macmillan NA, Creelman CD (1991) Detection theory: a user's guide. New York: Cambridge UP.

Majdandzic J, Bekkering H, van Schie HT, Toni I (2009) Movement-specific repetition suppression in ventral and dorsal premotor cortex during action observation. Cereb Cortex 19:2736-2745. CrossRef Medline

Manthey S, Schubotz RI, von Cramon DY (2003) Premotor cortex in observing erroneous action: an fMRI study. Brain Res Cogn Brain Res 15: 296-307. CrossRef Medline

Meister IG, Boroojerdi B, Foltys H, Sparing R, Huber W, Töpper R (2003) Motor cortex hand area and speech: implications for the development of language. Neuropsychologia 41:401-406. CrossRef Medline

Mills KR, Boniface SJ, Schubert M (1992) Magnetic brain stimulation with a double coil: the importance of coil orientation. Electroencephalogr Clin Neurophysiol 85:17-21. CrossRef Medline

Mitchell JP (2008) Contributions of functional neuroimaging to the study of social cognition. Curr Dir Psychol Sci 17:142-146. CrossRef

Mitchell JP (2009) Inferences about mental states. Philos Trans R Soc Lond B Biol Sci 364:1309-1316. CrossRef Medline

Molnar-Szakacs I, Iacoboni M, Koski L, Mazziotta JC (2005) Functional segregation within pars opercularis of the inferior frontal gyrus: evidence from fMRI studies of imitation and action observation. Cereb Cortex 15:986-994. CrossRef Medline

Moro V, Urgesi C, Pernigo S, Lanteri P, Pazzaglia M, Aglioti SM (2008) The neural basis of body form and body action agnosia. Neuron 60:235-246. CrossRef Medline

Pazzaglia M, Smania N, Corato E, Aglioti SM (2008) Neural underpinnings of gesture discrimination in patients with limb apraxia. J Neurosci 28: 3030-3041. CrossRef Medline

Pobric G, Hamilton AF (2006) Action understanding requires the left inferior frontal cortex. Curr Biol 16:524-529. CrossRef Medline

Press C, Heyes C, Kilner JM (2011) Learning to understand others' actions. Biol Lett 7:457-460. CrossRef Medline

Rossi S, Hallett M, Rossini PM, Pascual-Leone A, Pascual-Leone A (2009) Safety, ethical considerations, and application guidelines for the use of transcranial magnetic stimulation in clinical practice and research. Clin Neurophysiol 120:2008-2039. CrossRef Medline

Rossini PM, Barker AT, Berardelli A, Caramia MD, Caruso G, Cracco RQ, Dimitrijeviæ MR, Hallett M, Katayama Y, Lücking CH (1994) Noninvasive electrical and magnetic stimulation of the brain, spinal cord and 
roots: basic principles and procedures for routine clinical application. Report of an IFCN committee. Electroencephalogr Clin Neurophysiol 91:79-92. CrossRef Medline

Runeson S, Frykholm G (1983) Kinematic specification of dynamics as an informational bias for person-and-action perception: Expectation, gender recognition, and deceptive intent. J Exp Psychol 112:585-615.

Samson D, Apperly IA, Chiavarino C, Humphreys GW (2004) Left temporoparietal junction is necessary for representing someone else's belief. Nat Neurosci 7:499-500. CrossRef Medline

Saxe R, Powell LJ (2006) It's the thought that counts: specific brain regions for one component of theory of mind. Psychol Sci 17:692-699. CrossRef Medline

Saygin AP, Wilson SM, Hagler DJ Jr, Bates E, Sereno MI (2004) Point-light biological motion perception activates human premotor cortex. J Neurosci 24:6181-6188. CrossRef Medline

Schippers MB, Keysers C (2011) Mapping the flow of information within the putative mirror neuron system during gesture observation. Neuroimage 57:37-44. CrossRef Medline

Schippers MB, Gazzola V, Goebel R, Keysers C (2009) Playing charades in the fMRI: are mirror and/or mentalizing areas involved in gestural communication? PLoS One 4:e6801. CrossRef Medline

Schütz-Bosbach S, Prinz W (2007) Prospective coding in event representation. Cogn Proc 8:93-102. CrossRef Medline

Schütz-Bosbach S, Avenanti A, Aglioti SM, Haggard P (2009) Don't do it! Cortical inhibition and self-attribution during action observation. J Cogn Neurosci 21:1215-1227. CrossRef Medline

Sebanz N, Shiffrar M (2009) Detecting deception in a bluffing body: the role of expertise. Psychon Bull Rev 16:170-175. CrossRef Medline

Senot P, D’Ausilio A, Franca M, Caselli L, Craighero L, Fadiga L (2011) Effect of weight-related labels on corticospinal excitability during observation of grasping: a TMS study. Exp Brain Res 211:161-167. CrossRef Medline

Serino A, Canzoneri E, Avenanti A (2011) Fronto-parietal areas necessary for a multisensory representation of peripersonal space in humans: an rTMS study. J Cogn Neurosci 23:2956-2967. CrossRef Medline

Shmuelof L, Zohary E (2005) Dissociation between ventral and dorsal fMRI activation during object and action recognition. Neuron 47:457-470. CrossRef Medline
Spunt RP, Satpute AB, Lieberman MD (2011) Identifying the what, why, and how of an observed action: an fMRI study of mentalizing and mechanizing during action observation. J Cogn Neurosci 23:63-74. CrossRef Medline

Thioux M, Gazzola V, Keysers C (2008) Action understanding: how, what and why. Curr Biol 18:R431-R4. CrossRef Medline

Tokimura H, Tokimura Y, Oliviero A, Asakura T, Rothwell JC (1996) Speech-induced changes in corticospinal excitability. Ann Neurol 40: 628-634. CrossRef Medline

Uddin LQ, Iacoboni M, Lange C, Keenan JP (2007) The self and social cognition: the role of cortical midline structures and mirror neurons. Trends Cogn Sci 11:153-157. CrossRef Medline

Urgesi C, Candidi M, Ionta S, Aglioti SM (2007a) Representation of body identity and body actions in extrastriate body area and ventral premotor cortex. Nat Neurosci 10:30-31. CrossRef Medline

Urgesi C, Calvo-Merino B, Haggard P, Aglioti SM (2007b) Transcranial magnetic stimulation reveals two cortical pathways for visual body processing. J Neurosci 27:8023-8030. CrossRef Medline

Urgesi C, Maieron M, Avenanti A, Tidoni E, Fabbro F, Aglioti SM (2010) Simulating the future of actions in the human corticospinal system. Cereb Cortex 20:2511-2521. CrossRef Medline

Van Overwalle F, Baetens K (2009) Understanding others' actions and goals by mirror and mentalizing systems: a meta-analysis. Neuroimage 48:564-584. CrossRef Medline

van Schie HT, Mars RB, Coles MG, Bekkering H (2004) Modulation of activity in medial frontal and motor cortices during error observation. Nat Neurosci 7:549-554. CrossRef Medline

Vrij A (2004) Why professionals fail to catch liars and how they can improve. Legal and Criminological Psychology 9:159-181. CrossRef

Wilson M, Knoblich G (2005) The case for motor involvement in perceiving conspecifics. Psychol Bull 131:460-473. CrossRef Medline

Wolpert DM, Doya K, Kawato M (2003) A unifying computational framework for motor control and social interaction. Philos Trans R Soc Lond B Biol Sci 358:593-602. CrossRef Medline

Young L, Scholz J, Saxe R (2011) Neural evidence for "intuitive prosecution": The use of mental state information for negative moral verdicts. Soc Neurosci 6:302-315. CrossRef Medline 